\title{
CAPACIDADE COMBINATÓRIA E AÇÃO GÊNICA NA EXPRESSÃO DE CARACTERES DE IMPORTÂNCIA ECONÔMICA EM PIMENTÃO
}

\author{
Combining ability and gene action in the expression of \\ economically important traits in sweet pepper \\ Ildon Rodrigues do Nascimento ${ }^{1}$, Wilson Roberto Maluf ${ }^{2}$, Marcos Ventura Faria ${ }^{3}$,
Luiz Artur Costa do Valle ${ }^{4}$, Cícero Bezerra de Meneses ${ }^{2}$, Flávio Rodrigo Gandolfi Benites
}

\section{RESUMO}

Objetivou-se com o presente trabalho avaliar a capacidade combinatória de linhagens-elite de pimentão (Capsicum annиuт L.) e estudar os tipos de ação gênica envolvidos no controle de alguns dos caracteres de importância econômica, na tentativa de se identificar linhagens com potencial de originar híbridos competitivos com os atualmente plantados em escala comercial. O ensaio foi constituído de 30 híbridos, dos quais: (a) 18 obtidos num esquema dialélico Norte Carolina II, a partir do cruzamento de dois grupos de genitores [grupo I - genitores femininos: L-005, PIM-013, PIM-014, Magda, PIX021G_0818pl\#01 e PIX-022E31pl\#14; grupo II - genitores masculinos L-004, L-006 e MYR-29]; (b) cinco híbridos adicionais $\mathrm{F}_{1}$ (Hércules x L-004), $\mathrm{F}_{1}$ (Itapetininga x L-004), $\mathrm{F}_{1}\left(\mathrm{~L}-3509\right.$ Frutos amarelos x L-004), $\mathrm{F}_{1}\left(\mathrm{PIX}-021 \mathrm{~F} 0818\right.$ x L-006) e $\mathrm{F}_{1}(\mathrm{PIX}-$ 023E39 x L-006); (c) três híbridos entre os testadores $F_{1}\left(L-006\right.$ x L-004), $F_{1}\left(M Y R-29\right.$ x L-004) e $F_{1}(M Y R-29$ x L-006); (d) quatro híbridos comerciais (Magali R, Magali, Fortuna Super e Atenas). Utilizou-se o delineamento em blocos casualizados com 4 repetições. Avaliaram-se os seguintes caracteres: produção total, peso médio de frutos da produção total, produção precoce, comprimento de frutos, estrias nos frutos, profundidade de inserção do pedúnculo e altura de plantas. Houve predomínio dos efeitos gênicos aditivos para todas as características avaliadas, com exceção da produção total de frutos, em que os efeitos gênicos não-aditivos foram também importantes. Considerando os efeitos gênicos aditivos e não-aditivos conjuntamente, as melhores combinações foram $\mathrm{F}_{1}\left(\mathrm{PIM}-013\right.$ x MYR-29) e $\mathrm{F}_{1}(\mathrm{PIX}-022 \mathrm{E} 31 \mathrm{pl} \# 14$ x MYR-29), tanto para produção quanto para caracteres do fruto.

Termos para indexação: Capsicum annuum, híbridos, capacidade combinatória, análise dialélica.

\begin{abstract}
This paper reports on the combining ability and gene action among elite inbred lines of sweet pepper (Capsicum annuum L.), in an attempt to identify inbreds with good potencial to generate competitive commercial hybrids. The trial included 30 hybrid combinations: (a) 18 hybrids obtained via a North Carolina II scheme, representing hybrid combinations betwen two parental groups: group 1 - seed parents (L-005, PIM-013, PIM-014, Magda, PIX-021G_0818pl\#01 e PIX022E31pl\#14) and group 2 - polen parents (L-004, L-006 e MYR-29); (b) 5 additional experimental hybrids: $\mathrm{F}_{1}$ (Hércules x L-

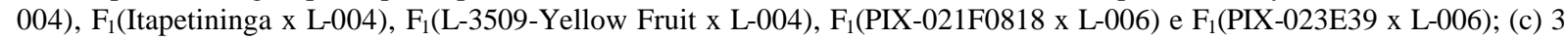
hybrids among the testers in group $2 \mathrm{~F}_{1}\left(\mathrm{~L}-006\right.$ x L-004), $\mathrm{F}_{1}\left(\mathrm{MYR}-29\right.$ x L-004) e $\mathrm{F}_{1}$ (MYR-29 x L-006); (d) 4 commercial hybrid checks (Magali R, Magali, Fortuna Super and Atenas). The hybrids were tested in a randomized complete block design with 4 replications. The following traits were evaluated: total yield, average fruit mass, early yield, fruit length, presence of cuticular stipples, penducle insertion depth, and plant height. Additive genetic effects predominated over non-additive effects for all traits studied, with the exception of total yield, a trait for wich non-additive effects were also important. Hybrid combinations $\mathrm{F}_{1}$ (PIM-013 x MYR-29) e $\mathrm{F}_{1}$ (PIX-022E31pl\#14 x MYR-29) stood out for their favorable general and specific combining ability effects for both yield and fruit related traits.
\end{abstract}

Index terms: Capsicum annuum, hybrid, combining ability, gene action, diallel analysis.

(Recebido para publicação em 28 de julho de 2003 e aprovado em 8 de outubro de 2003)

\footnotetext{
1. Doutorandos em Genética e Melhoramento de Plantas - Universidade Federal de Lavras/UFLA - Caixa Postal 37 - $37200-000$ - Lavras, MG. nascimento ildon@yahoo.com.br.

2. Departamento de Agricultura/UFLA. wrmaluf@ufla.br

3. Departamento de Agronomia/UNICENTRO - Universidade Estadual do Centro-Oeste - Guarapuava, PR

4. Engenheiro Agrônomo, Dr., Ministério da Agricultura.
} 


\section{INTRODUÇÃO}

A utilização de cultivares híbridas pelos produtores de pimentão (Capsicum annuum L.) tem sido importante fator para incremento da produtividade. A principal diferença entre essas cultivares e as tradicionalmente plantadas reside no efeito heterótico expresso nos caracteres diretamente ligados à produtividade e qualidade de frutos (TAVARES, 1993; INNECCO, 1995; OLIVEIRA, 1998; MIRANDA et al., 1998; BONETTI, 2002). Além disso, pode-se obter resistência para múltiplas doenças mais facilmente em híbridos do que em cultivares de polinização aberta.

Nas duas últimas décadas, ocorreram notáveis avanços nos programas de melhoramento do pimentão no Brasil, tanto que, nos dias atuais, a maioria das cultivares disponíveis nos catálogos das companhias de sementes são híbridos $F_{1}$. No entanto, apesar dos sucessos obtidos, ainda são muitos os desafios, que incluem a necessidade de melhor qualidade e conservação de frutos, maior resistência a doenças, maior produção total e precocidade.

A hibridação é uma das maneiras mais eficientes de explorar a variabilidade genética existente em muitas espécies. Entre os delineamentos genéticos para avaliação de novos híbridos, os cruzamentos dialélicos têm-se destacado, provendo também estimativas de parâmetros úteis na seleção de genitores para hibridação (CRUZ e CARNEIRO, 2003) e aumentando, na maioria das vezes, a eficiência dos programas de melhoramento.

Para o desenvolvimento de combinações híbridas com alto potencial produtivo, é necessária a identificação de linhagens parentais com boa capacidade combinatória, baseada na obtenção de estimativas da capacidade geral (CGC) e específica (CEC) de combinação. A primeira está relacionada aos efeitos gênicos de natureza aditiva e a segunda, aos efeitos gênicos não-aditivos (CATIGLIONI et al., 1999; HOLLAND, 2001). Para o pimentão, tem-se observado que além dos efeitos gênicos aditivos, os não-aditivos (dominância e/ou epistasia) têm sido de extrema importância, principalmente no aumento da produtividade (INNECCO, 1995; MELO, 1997; BONETTI, 2002).

Em estudo pioneiro da capacidade combinatória de linhagens de pimentão no Brasil, Miranda et al. (1998) verificou que os efeitos gênicos aditivos predominaram para número total de frutos por planta, número de frutos precoces, peso médio de frutos e relação comprimento/largura. Já Tavares (1993) verificou que apesar da significância dos efeitos gênicos aditivos, houve predomínio dos efeitos gênicos não-aditivos (dominância e/ou epistasia) para produção total de frutos por planta, peso de frutos precoce, altura de planta e número de dias para florescimento. Innecco (1995) verificou que os efeitos gênicos não-aditivos foram importantes para diversas características, em especial as relacionadas com a produção.

Estudando combinações híbridas de linhagens de pimentão quanto à tolerância ao baixo teor de fósforo no solo, Oliveira (1998) verificaram que os efeitos gênicos aditivos e, principalmente, os não-aditivos (dominância e/ou epistasia) estiveram envolvidos no controle da acumulação da matéria seca total e de outras características de crescimento e nutricionais avaliadas. Recentemente, Bonetti (2002) avaliou a capacidade combinatória de linhagens de pimentão e verificou maior importância dos efeitos gênicos aditivos, embora os efeitos gênicos não-aditivos tenham estado presentes para produção total e profundidade de inserção do pendúculo dos frutos.

Objetivou-se com o presente trabalho estimar a capacidade geral e específica de combinação em cruzamentos entre linhagens e/ou cultivares-elite do programa de melhoramento da Universidade Federal de Lavras/HortiAgro Sementes, e inferir sobre o tipo de ação gênica envolvido na expressão dos caracteres de importância econômica estudados.

\section{MATERIAL E MÉTODOS}

O experimento foi conduzido em casa-devegetação, na Estação Experimental da HortiAgro Sementes Ltda., situada no município de Ijaci-MG, entre os meses de março a novembro 2001. Os híbridos experimentais foram obtidos a partir de cruzamentos manuais e controlados realizados em estufas. O material experimental foi constituído de 30 híbridos simples, sendo: 18 obtidos num esquema dialélico Norte Carolina II, a partir do cruzamento de dois grupos de genitores [grupo I - genitores femininos: L-005, PIM-013, PIM014, Magda, PIX-021G_0818pl\#01 e PIX022E31pl\#14; grupo II - genitores masculinos L-004, L-006 e MYR-29]; cinco híbridos adicionais $\mathrm{F}_{1}$ (Hércules $\mathrm{x} \mathrm{L-004),} \mathrm{F}_{1}$ (Itapetininga x L-004), $\mathrm{F}_{1}(\mathrm{~L}-$ 3509-Frutos amarelos x L-004), $\mathrm{F}_{1}$ (PIX-021F0818 x L006) e $\mathrm{F}_{1}$ (PIX-023E39 x L-006); três híbridos entre os testadores $\mathrm{F}_{1}(\mathrm{~L}-006 \times \mathrm{L}-004), \mathrm{F}_{1}(\mathrm{MYR}-29 \times \mathrm{L}-004) \mathrm{e}$ $\mathrm{F}_{1}(\mathrm{MYR}-29$ x L-006); quatro híbridos comerciais, utilizados como testemunhas (Magali R, Magali, Fortuna Super e Atenas).

Ciênc. agrotec., Lavras, v. 28, n. 2, p. 251-260, mar./abr., 2004 
O delineamento experimental utilizado foi o de blocos casualizados com 4 repetições. Cada parcela experimental foi constituída por oito plantas no espaçamento de $1,0 \mathrm{~m}$ entre fileiras e $0,45 \mathrm{~m}$ entre plantas na fileira. Foram feitas onze colheitas escalonadas a cada sete dias entre 15 de agosto e 15 de novembro de 2001 . Cada parcela foi colhida separadamente, colhendo-se os frutos verdes no ponto de comercialização. As seguintes características foram avaliadas: produção total (PRODT), produção precoce (PRODP), peso médio de frutos da produção total (PMT), comprimento (COMP), presença de estrias (ESTRIAS), profundidade de inserção do pendúculo (PIP) e altura de plantas aos 187 dias após a emergência (ALT). Os valores obtidos em gramas/parcela para as características da produção foram convertidos em toneladas por hectare $\left(\mathrm{t} . \mathrm{ha}^{-1}\right)$. Para PRODP, considerou-se o somatório das produções das quatro primeiras colheitas.

A presença de estrias epidérmicas foi avaliada em 15 frutos colhidos aleatoriamente, com o auxílio de uma escala de notas, conforme a seguir: Nota 1 - fruto completamente liso, sem fenda na cutícula (desejável); Nota 2 - fruto com início de fenda superficial na cutícula; Nota 3 - fruto com fenda superficial na cutícula; Nota 4 - fruto com fenda de natureza não-progressiva na cutícula; Nota 5 - fruto com fenda progressiva e contínua na cutícula. Para o caráter PIP, atribuíram-se também notas de 0 a 5, conforme a seguinte escala: Nota 1 pedúnculo inserido no nível da base do fruto; Nota 2 pedúnculo inserido de 0 a $0,5 \mathrm{~cm}$ abaixo do nível da base do fruto; Nota 3 - de 0,5 a 1,0 cm abaixo do nível da base do fruto; Nota 4 - de 1,0 a 1,5 cm abaixo do nível da base do fruto e Nota 5 - mais de $1,5 \mathrm{~cm}$ abaixo do nível da base do fruto. Vale ressaltar que notas menores são desejáveis para os dois caracteres. Em ambas as características não foi necessário usar transformação.

A significância das médias foi verificada pelo teste de $\mathrm{F}$ e comparadas pelos critérios de agrupamentos de médias de Scott e Knott (1974) a 5\% de significância. Os quadrados médios da capacidade geral (CGC) e específica (CEC) de combinação foram obtidos para as pq=18 combinações híbridas resultantes do cruzamento entre $\mathrm{p}=6$ genitores do grupo 1 (feminino) e $\mathrm{q}=3$ testadores do grupo 2 (masculino), segundo o modelo estatístico: $y_{i j}=\grave{i}+g_{i}+g_{j}+s_{i j}+e_{i j}$, em que ì $=$ média geral; $\mathrm{g}_{\mathrm{i}}$ (efeito da CGC do parental do grupo 1) e $g_{j}$ (efeito da CGC do testador do grupo 2); $s_{i j}$ (efeito da CEC entre os genitores $\mathrm{i}$ e j); e $\mathrm{e}_{\mathrm{ij}}=$ erro experimental. Os estimadores de $g_{i}, g_{j}$ e $s_{i j}$, foram obtidos, adotando-se as seguintes restrições:

$$
\begin{aligned}
& \sum_{i} \hat{g}_{i}=0 ; \quad \sum_{j} \hat{g}_{j}=0 ; \quad \sum_{p} \hat{s}_{i j}=0 \quad i=1,2, \ldots p-1 ; \quad e \\
& \sum_{q} \hat{s}_{i j}=0 \quad j=1,2, \ldots q-1
\end{aligned}
$$

O comportamento médio dos grupos de híbridos foi verificada por meio da significância dos contrastes ortogonais na tabela de análise de variância (Tabela 1).

\section{RESULTADOS E DISCUSSÃO}

Diferenças significativas entre os tratamentos foram observadas para todas as características avaliadas (Tabela 1). Os efeitos dentro e entre os grupos de híbridos tiveram comportamento que variou em função do caráter e da característica considerada, indicando existência de variação genética para todos esses caracteres. Os efeitos de CGC foram significativos para todas as características no grupo 1 de genitores. Quanto a CGC no grupo 2 , não houve significância para PMT e PRODP apenas. A significância de CEC foi observada somente para PRODT (Tabela 1). Para esse conjunto de linhagens, os efeitos da CGC foram aparentemente a mais importante causa de variação genética entre as médias da tabela dialélica.

\section{Avaliação das médias das combinações híbridas}

Os caracteres da produção formaram dois grupos distintos para as três características avaliadas (Tabela 2). Para PRODT, 17 dos híbridos (65\% do total de tratamentos) experimentais tiveram comportamento estatisticamente semelhante às melhores testemunhas comerciais, destacando-se as combinações $\mathrm{F}_{1}(\mathrm{~L}-005 \mathrm{x}$ L006), $\mathrm{F}_{1}\left(\mathrm{PIM}-013\right.$ x MYR-29) e $\mathrm{F}_{1}(\mathrm{PIX}-$ 021G_0818pl\#01 x L-006) com valores respectivos de 68,$01 ; 65,58$ e 62,98 t.ha ${ }^{-1}$. Entre testemunhas comerciais, houve a formação de dois grupos para PMT. Entre as combinações experimentais, $13(50 \%)$ apresentaram PMT semelhantes às melhores testemunhas comerciais, destacando-se as combinações $\mathrm{F}_{1}$ (PIM-014 x L-004) e $\mathrm{F}_{1}$ (L-005 x L-004), com valores médios de 193,25 e 190,02 g.fruto ${ }^{-1}$, respectivamente. Quanto à produção precoce, as maiores médias (com valores respectivos de 30,$15 ; 27,52$ e 26,92 ton.ha $^{-1}$ ) foram obtidas nas combinações $\mathrm{F}_{1}$ (PIM-014 x L-004), $\mathrm{F}_{1}$ (MYR-29 x L004) e $F_{1}$ (PIM-013 x MYR-29), que se situaram no grupo dos tratamentos de maior PRODP, o qual incluiu três dos quatro híbridos comerciais usadas como testemunhas. 
TABELA 1 - Estimativas dos quadrados médios (QM), capacidade geral (CGC) e específica (CEC) de combinação, coeficientes de variação (CV \%) e médias referentes a sete caracteres avaliados em pimentão. Lavras: UFLA, 2001.

\begin{tabular}{|c|c|c|c|c|c|c|c|c|}
\hline \multirow{2}{*}{ Fontes de Variação } & \multicolumn{8}{|c|}{$\mathbf{Q M}$} \\
\hline & GL & PRODT & PMT & PRODP & COMP & ESTRIAS & PIP & ALT \\
\hline Blocos & 3 & 792,634 & 1189,097 & 694,384 & 214,062 & 0,496 & 0,033 & 1581,288 \\
\hline Tratamentos & 29 & $413,447 * *$ & $967,705 * *$ & $75,067 * *$ & $556,675 * *$ & $0,574 * *$ & $0,535 * *$ & $194,916 * *$ \\
\hline $\begin{array}{l}\text { Entre testemunhas \& híbridos adicionais \& } \\
\text { híbridos entre testadores }\end{array}$ & 11 & 354,875 & $1070,807 *$ & 322,007 & $370,906 * *$ & $0,310 *$ & $0,515 * *$ & 160,836 \\
\hline $\begin{array}{l}\text { Testemunhas vs híbridos experi- } \\
\text { mentais não incluídos no dialelo NC II }\end{array}$ & 1 & $1208,775 *$ & 180,319 & 143,742 & 116,336 & 0,056 & 0,018 & 344,700 \\
\hline Entre testemunhas comerciais & 3 & 82,691 & 241,279 & $46,626 *$ & 83,254 & $0,653 *$ & 0,038 & 85,470 \\
\hline $\begin{array}{l}\text { Entre híbridos adicionais \& híbri- } \\
\text { dos entre testadores }\end{array}$ & 7 & 349,539 & $1553,532 * *$ & 75,620 & $530,552 * *$ & 0,198 & $0,790 * *$ & 166,869 \\
\hline Entre híbridos adicionais & 4 & 402,539 & $2259,223 * *$ & 64,368 & $677,827 * *$ & 0,095 & $1,176 * *$ & 166,754 \\
\hline $\begin{array}{l}\text { Híbridos adicionais vs híbridos } \\
\text { entre testadores }\end{array}$ & 1 & 347,770 & 428,482 & $196,211 *$ & 3,390 & $0,763 *$ & 0,013 & 167,147 \\
\hline Entre híbridos entre testadores & 2 & 244,265 & 342,757 & 37,829 & $499,583 *$ & 0,122 & $0,407 * *$ & 166,960 \\
\hline $\begin{array}{l}\text { Testemunhas \& híbridos adicionais \& híbri- } \\
\text { dos entre testadores vs híbridos do dialelo NC II }\end{array}$ & 1 & 45,150 & 11,866 & 20,723 & $635,083 * *$ & $1,486 * *$ & $0,716 * *$ & 11,641 \\
\hline Entre híbridos do dialelo NC II & 17 & 473,012 & $957,218 * *$ & $79,015 * *$ & $672,267 * *$ & $0,692 * *$ & $0,538 * *$ & $227,750 * *$ \\
\hline CGC Genitores femininos (grupo 1) & 5 & $559,112 *$ & $2497,024 * *$ & $140,764 * *$ & $675,625 * *$ & $1,189 * *$ & $1,107 * *$ & $458,173 * *$ \\
\hline CGC Genitores masculinos (grupo 2) & 2 & $581,666 *$ & 547,884 & 46,926 & $3225,117 * *$ & $1,811 * *$ & $1,505 * *$ & $380,061 *$ \\
\hline $\begin{array}{l}\text { CEC (Genitores do grupo } 1 \times \text { Genito- } \\
\text { res do grupo 2) }\end{array}$ & 10 & $408,231 *$ & 269,181 & 54,559 & 160,018 & 0,219 & 0,060 & 82,076 \\
\hline Resíduo & 87 & 189,203 & 293,151 & 38,736 & 82,767 & 0,133 & 0,054 & 98,551 \\
\hline CV\% & & 27,305 & 10,375 & 28,929 & 6,253 & 21,246 & 10,987 & 9,367 \\
\hline Média & & 50,377 & 165,030 & 21,514 & 145,481 & 1,721 & 2,133 & 105,973 \\
\hline
\end{tabular}

**,* Significativo a 1 e $5 \%$ de probalidade pelo teste de $\mathbf{F}$.

Ciênc. agrotec., Lavras, v. 28, n. 2, p. 251-260, mar./abr., 2004 
Em relação aos caracteres do fruto, houve a formação de três grupos distintos para COMP, com a maioria dos híbridos apresentando comportamento semelhante ao das testemunhas comerciais; porém, mereceram destaque os valores médios das combinações $F_{1}$ (PIX-021G_0818pl\#01 x MYR-29), F F $_{1}$ (PIX022E31pl\#14 x MYR-29) e $F_{1}($ PIX-022E31pl\#14 x L-006), pertencentes ao grupo 1 (grupo de frutos com maior comprimento), com valores respectivos de $170,50 \mathrm{~mm}, 168,25 \mathrm{~mm}$ e $161,53 \mathrm{~mm}$ (Tabela 2). Um importante fator também considerado foi a presença de estrias epidérmicas nos frutos, e para esse caráter, valores próximos de 1,0, na escala de notas adotada, são os ideais. Nesse aspecto, destacaram-se as combinações $\mathrm{F}_{1}$ (PIX-023E09 x L-006) e $\mathrm{F}_{1}$ (PIX021G_0818pl\#01 x L-006), com notas médias respectivas de 1,16 e 1,21, as quais foram semelhantes às melhor testemunha comercial sob esse aspecto (Magali R). Para o caráter PIP, valores próximos de 1,0 também são os ideais. Nos grupos de híbridos, houve a formação de quatro grupos, com destaque para as combinações $F_{1}$ (PIX-021G_0818pl\#01 x MYR-29) e $F_{1}$ (PIX-021G_0818pl\#01 x L-006), com valores de 1,42 e 1,48, respectivamente, valores esses melhores do que os obtidos para as testemunhas comerciais avaliadas. Para altura das plantas aos 187 dias após a emergência (ALT), houve a formação de apenas dois grupos distintos entre os híbridos experimentais e testemunhas comerciais, mostrando aparentemente pouca variação genética para o caráter (Tabela 2).

Para as atuais exigências do mercado, entre os vários híbridos experimentais, destacaram-se $\mathrm{F}_{1}$ (PIM-013 x MYR-29) e $\mathrm{F}_{1}$ (PIX-022E31pl\#31 x MYR-29) que, além de produtivos, possuem frutos de bom formato comercial, reunindo efeitos desejáveis para COMP, ESTRIAS, PIP e ALT. Vale destacar que o híbrido $F_{1}$ (PIM-013 x MYR-29) é resistente a potyvirus (especialmente PepYMV = Pepper Yellow Mosaic Virus, syn. PVY ${ }^{\mathrm{m}}$ ) (VALLE, 2002a) e tolerante a Phytophthora capsici (VALLE, 2002b). A combinação $F_{1}(M Y R-29 \times$ L-006) possui resistência a PepYMV (VALLE, 2002a). Com esses resultados, constata-se que é possível produzir híbridos adaptados produtivos e precoces, e que, sendo mais uniformes quanto ao porte e ciclo, apresentam vantagens sobre muitos dos padrões estabelecidos pelos híbridos comerciais.

\section{Avaliação dos genitores quanto à CGC e CEC Produção total de frutos (PRODT)}

As estimativas da CGC no grupo de genitores femininos $\left(\mathrm{g}_{\mathrm{i}}\right)$ para PRODT variaram de $-9,940$ a 9,110 t.ha ${ }^{-1}$ (amplitude de 19,500 t.ha ${ }^{-1}$ ), ao passo que para o grupo de genitores masculinos $\left(\mathrm{g}_{\mathrm{j}}\right)$, variaram de $-5,639$ a 3,001 t.ha ${ }^{-1}$ (amplitude de 8,640 t.ha $^{-1}$ ) (Tabela 3). A significância e o alto valor positivo da estimativa da CGC indicam alta frequiência de genes favoráveis de natureza aditiva (CRUZ e CARNEIRO, 2003). As linhagens L-005, PIX021-G_0818pl\#01 e PIM-013 (genitores femininos) e MYR-29 e L-006 (genitores masculinos), com estimativas respectivas da CGC de 9,110;4,519; 1,986; 3,001 e 2,638 t.ha ${ }^{-1}$ parecem ser, pois, úteis em programas de melhoramento, visando à seleção de novas linhagens e/ou à obtenção de híbridos mais produtivos.

Para a obtenção de híbridos, as estimativas da CEC têm importante significado genético, tanto no que se refere ao seu sinal quanto à sua magnitude relativa (HOLLAND, 2001). Nesse aspecto, as estimativas dos componentes de média das CEC $\left(\mathrm{s}_{\mathrm{ij}}\right)$ variaram de $-10,197$ a 14,771 t.ha ${ }^{-1}$ (amplitude de 24,974 t.ha $^{-1}$ ) (Tabela 3), que é bastante representativa perante a média $\left(\mu=49,875 \mathrm{t}^{-h a^{-1}}\right)$, e indicativa de que, além dos efeitos gênicos aditivos, os não-aditivos (dominância e/ou epistasia) também são importantes na expressão do caráter.

Estimativas positivas das CEC's pertencem aos híbridos $\mathrm{F}_{1}$ (PIX-022E31pl\#14 x MYR-29), $\mathrm{F}_{1}$ (PIM-013 x MYR-29) e $\mathrm{F}_{1}$ (PIM-014 x L-004) com valores de $14,771,10,717$ e 8,096 t.ha ${ }^{-1}$, respectivamente (Tabela 3). Os híbridos $\mathrm{F}_{1}$ (PIX-022E31pl\#14 x MYR-29) e $F_{1}$ (PIM-013 x MYR-29) possuem além de alto valor para CEC, pelo menos um dos genitores com alto valor de CGC, o que é desejável. Na combinação $\mathrm{F}_{1}$ (PIM-014 x L-004), ambos os genitores apresentam valores negativos de CGC, presumindo-se que os efeitos gênicos não-aditivos foram mais importantes para a superioridade dessa combinação híbrida. Os autores Tavares (1993), Innecco (1995), Soares (1995), Miranda et al. (1998), Maluf et al. (1999) e Bonetti (2002) encontraram heterose significativa para produção total de frutos, que pode ser atribuída, possivelmente, à maior importância dos efeitos gênicos de natureza não-aditiva. 
TABELA 2 - Estimativas de médias referentes a sete caracteres avaliados em híbridos de pimentão. Lavras: UFLA, 2001.

\begin{tabular}{|c|c|c|c|c|c|c|c|}
\hline Trat & $\begin{array}{c}\text { PRODT } \\
\left(\text { t.ha }^{-1}\right)\end{array}$ & $\begin{array}{l}\text { PMT } \\
\left(\text { g.fruto }^{-1}\right)\end{array}$ & $\begin{array}{c}\text { PRODP } \\
\left(\text { t.ha }^{-1}\right)\end{array}$ & $\begin{array}{c}\text { COMP } \\
(\mathrm{mm})\end{array}$ & ESTRIAS & PIP & $\begin{array}{r}\text { ALT } \\
(\mathbf{c m})\end{array}$ \\
\hline Magali R F & $759 \mathrm{~A}$ & $162,11 \mathrm{~B}$ & $20,83 \mathrm{~B}$ & $149,15 \mathrm{~B}$ & $1,16 \mathrm{~B}$ & $2,20 \mathrm{C}$ & $109,12 \mathrm{~A}$ \\
\hline Magali $F_{1}$ & $52,82 \mathrm{~A}$ & $177,93 \mathrm{~A}$ & $23,41 \mathrm{~A}$ & $145,73 \mathrm{C}$ & $1,88 \mathrm{~A}$ &, $15 \mathrm{C}$ & $104,10 \mathrm{~B}$ \\
\hline Fortuna Super $F_{1}$ & $63,91 \mathrm{~A}$ & $161,01 \mathrm{~B}$ & $24,61 \mathrm{~A}$ & $138,41 \mathrm{C}$ & $1,43 \mathrm{~B}$ & $2,11 \mathrm{C}$ & $114,59 \mathrm{~A}$ \\
\hline Atenas $\mathrm{F}_{1}$ & $58,56 \mathrm{~A}$ & $168,50 \mathrm{~A}$ & $29,01 \mathrm{~A}$ & $146,16 \mathrm{C}$ & $2,04 \mathrm{~A}$ & $2,33 \mathrm{~B}$ & $112,75 \mathrm{~A}$ \\
\hline F & $46,39 \mathrm{~B}$ & $156,60 \mathrm{~B}$ & $19,01 \mathrm{~B}$ & $132,07 \mathrm{D}$ & $1,48 \mathrm{~B}$ & $2,13 \mathrm{C}$ & $97,50 \mathrm{~B}$ \\
\hline $\mathrm{F}_{1}($ Itapetininga_x_L-004) & $61,53 \mathrm{~A}$ & $180,54 \mathrm{~A}$ & $25,01 \mathrm{~A}$ & $142,42 \mathrm{C}$ & $1,51 \mathrm{~B}$ & $2,93 \mathrm{~A}$ & $109,02 \mathrm{~A}$ \\
\hline $\mathrm{F}_{1}(\mathrm{~L}-3509$ Frutos Amarelos x L-004) & $42,13 \mathrm{~B}$ & $186,64 \mathrm{~A}$ & $19,68 \mathrm{~B}$ & $125,43 \mathrm{D}$ & $1,50 \mathrm{~B}$ & $2,58 \mathrm{~A}$ & $94,86 \mathrm{~B}$ \\
\hline F 1 (PIX-021F0818_x_L-006) & $39,45 \mathrm{~B}$ & $150,45 \mathrm{~B}$ & $16,05 \mathrm{~B}$ & $158,36 \mathrm{~B}$ & $1,53 \mathrm{~B}$ & $1,58 \mathrm{D}$ & $108,87 \mathrm{~A}$ \\
\hline $\mathrm{F}_{1}\left(\mathrm{PIX}-023 \mathrm{E} 09 \_\mathrm{x} \_L-006\right)$ & $35,60 \mathrm{~B}$ & $127,97 \mathrm{~B}$ & $14,63 \mathrm{~B}$ & $148,26 \mathrm{~B}$ & $1,16 \mathrm{~B}$ & $1,87 \mathrm{C}$ & $103,18 \mathrm{~B}$ \\
\hline $\mathrm{F}_{1}\left(\mathrm{~L}-006 \_\mathrm{x} \_\mathrm{L}-004\right)$ & $42,99 \mathrm{~B}$ & $170,13 \mathrm{~A}$ & $21,87 \mathrm{~A}$ & $130,58 \mathrm{D}$ & $1,94 \mathrm{~A}$ & $2,28 \mathrm{~B}$ & $101,17 \mathrm{~B}$ \\
\hline F 1 (MYR-29_x_L-004) & $57,82 \mathrm{~A}$ & $180,08 \mathrm{~A}$ & $27,52 \mathrm{~A}$ & $142,43 \mathrm{C}$ & $1,73 \mathrm{~B}$ & $2,57 \mathrm{~A}$ & $106,98 \mathrm{~A}$ \\
\hline F 1 (MYR-29_x_L-006) & $54,68 \mathrm{~A}$ & $153,79 \mathrm{~B}$ & $22,59 \mathrm{~A}$ & $152,92 \mathrm{~B}$ & $1,60 \mathrm{~B}$ & $1,93 \mathrm{C}$ & $114,07 \mathrm{~A}$ \\
\hline $\mathrm{F}_{1}\left(\mathrm{~L}-005 \_\mathrm{x} \_\mathrm{L}-004\right)$ & $55,52 \mathrm{~A}$ & $190,02 \mathrm{~A}$ & $26,24 \mathrm{~A}$ & $131,49 \mathrm{D}$ & $2,21 \mathrm{~A}$ & $2,61 \mathrm{~A}$ & $97,19 \mathrm{~B}$ \\
\hline $\mathrm{F}_{1}\left(\mathrm{~L}-005 \_\mathrm{X} \_\mathrm{L}-006\right)$ & $68,01 \mathrm{~A}$ & $187,52 \mathrm{~A}$ & $24,93 \mathrm{~A}$ & $141,08 \mathrm{C}$ & $1,36 \mathrm{~B}$ & $2,15 \mathrm{C}$ & $94,15 \mathrm{~B}$ \\
\hline $\mathrm{F}_{1}\left(\mathrm{~L}-005 \_\mathrm{x} \_\mathrm{MYR}-29\right)$ & $53,42 \mathrm{~A}$ & $179,98 \mathrm{~A}$ & $21,57 \mathrm{~B}$ & $136,31 \mathrm{C}$ & $1,80 \mathrm{~B}$ & $2,13 \mathrm{C}$ & $95,03 \mathrm{~B}$ \\
\hline $\mathrm{F}_{1}\left(\mathrm{PIM}-013 \_\mathrm{x} \_L-004\right)$ & $36,02 \mathrm{~B}$ & $166,31 \mathrm{~A}$ & $18,89 \mathrm{~B}$ & $126,08 \mathrm{D}$ & $2,41 \mathrm{~A}$ & $2,55 \mathrm{~A}$ & $96,88 \mathrm{~B}$ \\
\hline $\mathrm{F}_{1}\left(\mathrm{PIM}-013 \_\mathrm{x} \_L-006\right)$ & & & & $\mathrm{B}$ & & & $39 \mathrm{~A}$ \\
\hline F & A & 175 & & 150,2 & $2,30 \mathrm{~A}$ & & $112,96 \mathrm{~A}$ \\
\hline F 1 (PIM-014_x_L-004) & $51,80 \mathrm{~A}$ & $193,25 \mathrm{~A}$ & $30,15 \mathrm{~A}$ & $133,57 \mathrm{D}$ & $1,88 \mathrm{~A}$ & $2,78 \mathrm{~A}$ & $106,44 \mathrm{~A}$ \\
\hline F & $43,41 \mathrm{~B}$ & $166,52 \mathrm{~A}$ & $16,96 \mathrm{~B}$ & $157,63 \mathrm{~B}$ & $1,48 \mathrm{~B}$ & $2,00 \mathrm{C}$ & $101,97 \mathrm{~B}$ \\
\hline FilPIM-014_x_MYR-29) & $52,82 \mathrm{~A}$ & $172,99 \mathrm{~A}$ & $26,86 \mathrm{~A}$ & $157,76 \mathrm{~B}$ & $1,68 \mathrm{~B}$ & $2,26 \mathrm{~B}$ & $114,70 \mathrm{~A}$ \\
\hline $\mathrm{F}_{1}(\mathrm{MAGDA}$ _x_L-004) & $42,40 \mathrm{~B}$ & $156,92 \mathrm{~B}$ & $18,49 \mathrm{~B}$ & $137,55 \mathrm{C}$ & $2,35 \mathrm{~A}$ & $1,93 \mathrm{C}$ & $99,47 \mathrm{~B}$ \\
\hline $\mathrm{F}_{1}(\mathrm{MAGDA} \mathrm{A}$ _L-006) & $43,65 \mathrm{~B}$ & $144,14 \mathrm{~B}$ & $16,00 \mathrm{~B}$ & $145,45 \mathrm{C}$ & $1,53 \mathrm{~B}$ & $1,78 \mathrm{D}$ & $103,04 \mathrm{~B}$ \\
\hline F(MAGDA_x_MYR-29) & $33,74 \mathrm{~B}$ & $146,30 \mathrm{~B}$ & $14,60 \mathrm{~B}$ & $149,13 \mathrm{~B}$ & $1,46 \mathrm{~B}$ & $1,71 \mathrm{D}$ & $102,43 \mathrm{~B}$ \\
\hline F1(PIX-021G_0818p1\#01_x_L-004) & $48,36 \mathrm{~B}$ & $156,65 \mathrm{~B}$ & $20,31 \mathrm{~B}$ & $138,65 \mathrm{C}$ & $2,16 \mathrm{~A}$ & $1,83 \mathrm{C}$ & $106,63 \mathrm{~A}$ \\
\hline 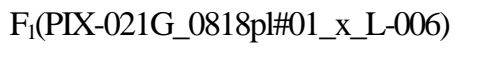 & $62,98 \mathrm{~A}$ & $151,98 \mathrm{~B}$ & $19,57 \mathrm{~B}$ & $156,08 \mathrm{~B}$ & $1,21 \mathrm{~B}$ & $1,48 \mathrm{D}$ & $112,80 \mathrm{~A}$ \\
\hline Fl(PIX-021G_0818pl\#01_x_MYR-29) & $51,83 \mathrm{~A}$ & $156,11 \mathrm{~B}$ & $21,21 \mathrm{~B}$ & $170,50 \mathrm{~A}$ & $1,71 \mathrm{~B}$ & $1,42 \mathrm{D}$ & $118,75 \mathrm{~A}$ \\
\hline $\mathrm{F}_{1}\left(\mathrm{PIX}-022 \mathrm{E} 31 \mathrm{pl} \# 14 \_\mathrm{x} \_L-004\right)$ & $31,29 \mathrm{~B}$ & $151,68 \mathrm{~B}$ & $17,67 \mathrm{~B}$ & $137,05 \mathrm{C}$ & $1,66 \mathrm{~B}$ & $2,40 \mathrm{~B}$ & $103,21 \mathrm{~B}$ \\
\hline $\mathrm{F}_{1}\left(\mathrm{PIX}-022 \mathrm{E} 31 \mathrm{pl} \# 14 \_\mathrm{x} \_L-006\right)$ & $40,38 \mathrm{~B}$ & $145,79 \mathrm{~B}$ & $16,01 \mathrm{~B}$ & $161,53 \mathrm{~A}$ & $1,36 \mathrm{~B}$ & $1,93 \mathrm{C}$ & $111,19 \mathrm{~A}$ \\
\hline F (PIX-022E31pl\#14_x_MYR-29) & $62,50 \mathrm{~A}$ & $170,22 \mathrm{~A}$ & $20,83 \mathrm{~B}$ & $168,25 \mathrm{~A}$ & $1,45 \mathrm{~B}$ & $2,18 \mathrm{C}$ & $113,65 \mathrm{~A}$ \\
\hline
\end{tabular}

Médias com mesma letra na coluna, não apresentam diferenças significativas pelo teste de Scott Knott $(P=5 \%)$.

Ciênc. agrotec., Lavras, v. 28, n. 2, p. 251-260, mar./abr., 2004 
TABELA 3 - Estimativas da capacidade geral $\left(g_{i}\right.$ e $\left.g_{j}\right)$ e específica $\left(s_{i j}\right)$ de combinação dos componentes de média para sete caracteres avaliados em híbridos de pimentão. Lavras: UFLA, 2001.

\begin{tabular}{|c|c|c|c|c|c|c|c|}
\hline & PRODT & PMT & PRODP & COMP & ESTRIA & PIP & ALT \\
\hline$\mu$ & 49,875 & 165,285 & 21,174 & 147,360 & 1,811 & 2,069 & 105,719 \\
\hline \multicolumn{8}{|l|}{$\mathrm{g}_{\mathrm{i}}$} \\
\hline $\mathrm{L}-005\left(\mathrm{~g}_{1}\right)$ & 9,110 & 20,553 & 3,073 & $-11,063$ & $-0,017$ & 0,230 & $-10,257$ \\
\hline PIM-013 $\left(\mathrm{g}_{2}\right)$ & 1,986 & 3,082 & 2,058 & $-3,893$ & 0,603 & 0,126 & 1,693 \\
\hline PIM-014 ( $\left.\mathrm{g}_{3}\right)$ & $-0,527$ & 12,297 & 3,488 & 2,298 & $-0,128$ & 0,280 & 1,984 \\
\hline $\operatorname{MAGDA}\left(\mathrm{g}_{4}\right)$ & $-9,940$ & $-16,170$ & $-4,809$ & $-3,314$ & $-0,028$ & $-0,256$ & $-4,066$ \\
\hline PIX021-G_0818pl\#01 ( $\left.\mathrm{g}_{5}\right)$ & 4,519 & $-10,372$ & $-0,807$ & 7,719 & $-0,111$ & $-0,486$ & 7,011 \\
\hline PIX022-E31pl\#14 (g $\left.{ }_{6}\right)$ & $-5,147$ & $-9,390$ & $-3,002$ & 8,253 & 0,316 & 0,105 & 3,636 \\
\hline \multicolumn{8}{|l|}{$\mathrm{g}_{\mathrm{j}}$} \\
\hline $\mathrm{L}-004\left(\mathrm{~g}_{1}\right)$ & $-5,639$ & 3,850 & 0,786 & $-13,293$ & 0,304 & 0,284 & $-4,079$ \\
\hline $\mathrm{L}-006\left(\mathrm{~g}_{2}\right)$ & 2,638 & $-6,416$ & $-1,937$ & 6,341 & $-0,274$ & $-0,223$ & 0,248 \\
\hline $\operatorname{MYR}-29\left(\mathrm{~g}_{3}\right)$ & 3,001 & 2,566 & 1,150 & 6,952 & $-0,030$ & $-0,061$ & 3,831 \\
\hline \multicolumn{8}{|l|}{$\mathrm{s}_{\mathrm{ij}}$} \\
\hline F1(L-005_x_L-004) $\left(\mathrm{s}_{11}\right)$ & 2,173 & 0,332 & 1,206 & 8,486 & 0,118 & 0,027 & 5,814 \\
\hline $\mathrm{F} 1\left(\mathrm{~L}-005 \_\mathrm{X} \_\mathrm{L}-006\right)\left(\mathrm{s}_{12}\right)$ & 6,391 & 8,097 & 2,619 & $-1,550$ & $-0,154$ & 0,073 & $-1,558$ \\
\hline F1(L-005_x_MYR-29) $\left(\mathrm{s}_{13}\right)$ & $-8,564$ & $-8,430$ & $-3,825$ & $-6,936$ & 0,036 & $-0,101$ & $-4,256$ \\
\hline F1(PIM-013_x_L-004) $\left(\mathrm{s}_{21}\right)$ & $-10,197$ & $-5,908$ & $-5,126$ & $-4,086$ & $-0,305$ & 0,069 & $-6,454$ \\
\hline F1(PIM-013_x_L-006) $\left(\mathrm{s}_{22}\right)$ & $-0,519$ & 1,733 & 2,582 & 4,255 & 0,391 & $-0,035$ & 4,730 \\
\hline F1(PIM-013_x_MYR-29) $\left(\mathrm{s}_{23}\right)$ & 10,717 & 4,175 & 2,544 & $-0,169$ & $-0,085$ & $-0,034$ & 1,724 \\
\hline F1(PIM-014_x_L-004) $\left(\mathrm{s}_{31}\right)$ & 8,096 & 11,811 & 4,707 & $-2,791$ & $-0,105$ & 0,152 & 2,815 \\
\hline F1(PIM-014_x_L-006) $\left(\mathrm{s}_{32}\right)$ & $-8,568$ & $-4,649$ & $-5,758$ & 1,639 & 0,076 & $-0,126$ & $-5,981$ \\
\hline F1(PIM-014_x_MYR-29) $\left(\mathrm{s}_{33}\right)$ & 0,471 & $-7,161$ & 1,050 & 1,152 & 0,029 & $-0,026$ & 3,166 \\
\hline F1(MAGDA_x_L-004) $\left(\mathrm{s}_{41}\right)$ & 8,111 & 3,949 & 1,338 & 6,797 & 0,261 & $-0,159$ & 1,903 \\
\hline F1(MAGDA_x_L-006) $\left(\mathrm{s}_{42}\right)$ & 1,084 & 1,436 & 1,574 & $-4,937$ & 0,023 & 0,198 & 1,147 \\
\hline F1(MAGDA_x_MYR-29) $\left(\mathrm{s}_{43}\right)$ & $-9,196$ & $-5,386$ & $-2,913$ & $-1,860$ & $-0,285$ & $-0,038$ & $-3,049$ \\
\hline F1(PIX-021G_0818pl\#01_x_L-004) (s (s1) & $-0,390$ & $-2,113$ & $-0,838$ & $-3,136$ & 0,162 & $-0,030$ & $-2,019$ \\
\hline F1(PIX-021G_0818pl\#01_x_L-006) s(52) & 5,952 & 3,485 & 1,140 & $-5,332$ & $-0,208$ & 0,127 & $-0,178$ \\
\hline $\begin{array}{l}\mathrm{F} 1 \text { (PIX-021G_0818pl\#01_x_MYR-29) } \\
\left(\mathrm{s}_{53}\right)\end{array}$ & $-5,561$ & $-1,371$ & $-0,302$ & 8,469 & 0,045 & $-0,096$ & 2,197 \\
\hline F1(PIX-022E31pl\#14_x_L-004) $\left(\mathrm{s}_{61}\right)$ & $-7,793$ & $-8,071$ & $-1,288$ & $-5,270$ & $-0,132$ & $-0,059$ & $-2,059$ \\
\hline F1(PIX-022E31pl\#14_x_L-006) $\left(\mathrm{s}_{62}\right)$ & $-6,978$ & $-3,686$ & $-0,221$ & $-0,416$ & 0,146 & $-0,014$ & 1,592 \\
\hline $\mathrm{F} 1\left(\mathrm{PIX}-022 \mathrm{E} 31 \mathrm{pl} \# 14 \_\mathrm{x} \_\mathrm{MYR}-29\right)\left(\mathrm{s}_{63}\right)$ & 14,771 & 11,758 & 1,509 & 5,685 & $-0,014$ & 0,073 & 0,467 \\
\hline
\end{tabular}




\section{Peso médio de frutos da produção total (PMT)}

As estimativas significativas de CGC do grupo de genitores femininos $\left(\mathrm{g}_{\mathrm{i}}\right)$ variaram de $-16,170$ a 20,553 g.fruto ${ }^{-1}$ (amplitude de 36,723 g.fruto ${ }^{-1}$ ) (Tabela 3 ). Entre os genitores masculinos, as estimativas de CGC $\left(g_{j}\right)$ variaram de $-6,416$ a 3,850 g.fruto ${ }^{-1}$ (amplitude de 10,266 g.fruto $^{-1}$ ), indicando pouca influência na média do caráter e refletindo em uma CGC nãosignificativa para esse grupo de genitores (Tabela 1). Os valores das estimativas das CEC's variaram de $-8,430$ a 11,811 g.fruto $^{-1}$ (amplitude de 20,241 g.fruto $\left.{ }^{-1}\right)$, valores esses menos relevantes comparandose à média geral $\left(165,285\right.$ g.fruto $\left.^{-1}\right)$, o que refletiu na não-significância da CEC (Tabela 1). Com esses resultados, verifica-se que o grupo de genitores femininos aqui utilizado tem maior influência na média do caráter nos híbridos avaliados do que o grupo de genitores usados como fonte de pólen. Como valores positivos e significativos da CGC são desejáveis, destacam-se quanto a essa característica os genitores L-005 e PIM-014 (Tabela 3). A não-significância da CEC indica pouca importância relativa dos efeitos gênicos não-aditivos para PMT. O predomínio de efeitos gênicos aditivos controlando o caráter está de acordo com os resultados de Tavares (1993), Miranda et al. (1998) e Bonetti (2002), mas é contrário aos resultados de Innecco (1995).

\section{Produção precoce de frutos (PRODP)}

A CGC para PRODP, no grupo de genitores femininos $\left(\mathrm{g}_{\mathrm{i}}\right.$ ), variaram de $-4,809$ a 3,448 t.ha ${ }^{-1}$ (amplitude de 8,297 t.ha $^{-1}$ ), destacando-se os genitores PIM014, L-005 e PIM-013, com valores respectivos de $3,488,3,073$ e 2,058 t.ha ${ }^{-1}$, tendo, portanto, uma maior influência na média dos caracteres nas combinações híbridas das quais participam (Tabela 3 ).

Embora a CEC's tenha variado de $-5,758$ a 4,707 (amplitude de 10,465 t.ha ${ }^{-1}$ ), essa não foi significativa, porém é de importante significado quando comparado com a média geral $\left(\mu=21,174\right.$ t.ha $\left.^{-1}\right)$ (Tabela 3$)$. A CGC dos genitores masculinos não foram significativas, indicando que esses genitores aparentemente apresentam pouca influência na média do caráter nas combinações aqui avaliadas. A CEC não-significativa indica pouca importância relativa dos efeitos gênicos nãoaditivos, concordando com os resultados de Tavares (1993), Miranda et al. (1998) e Bonetti (2002) e discordando de Innecco (1995), que encontrou maior importância relativa dos efeitos gênicos não-aditivos.

\section{Comprimento dos frutos (COMP)}

Para os genitores femininos $\left(\mathrm{g}_{\mathrm{i}}\right)$, a CGC variou de $-11,063$ a $8,685 \mathrm{~mm}$ (amplitude de 19,748 mm), ao passo que para o grupo de genitores masculinos $\left(\mathrm{g}_{\mathrm{j}}\right)$, variou de $-13,293$ a 6,952 (amplitude de 20,245 mm) (Tabela 3). Pelos valores estimados, os genitores femininos e masculinos apresentaram influência semelhante na média dos híbridos avaliados. Destacam-se as estimativas observadas para PIX-022E31pl\#14, PIX021G_0818pl\#01 e PIM-014 (com valores respectivos de $8,253 \mathrm{~mm} ; 7,719 \mathrm{~mm}$ e 2,298 $\mathrm{mm}$ ) no grupo dos genitores femininos, e MYR-29 e L-006 (com valores respectivos de $6,952 \mathrm{~mm}$ e $6,341 \mathrm{~mm}$ ) no grupo de genitores masculinos.

Valores positivos para as estimativas da CEC's foram observados, porém, esses não foram significativos (Tabela 1). Pelas suas magnitudes, merecem destaque os valores das combinações $\mathrm{F}_{1}(\mathrm{~L}-005 \times \mathrm{x}$ L-004), $\mathrm{F}_{1}$ (PIX-021G 0818pl\#01 x MYR-29) $\mathrm{F}_{1}$ (MAGDA x L004), $F_{1}\left(\right.$ PIX-022E31pl\#14 x MYR-29) e $F_{1}$ (PIM-013 x L-006) (Tabela 3). Nas combinações híbridas $F_{1}$ (PIX021G 0818pl\#01 x MYR-29) e F (PIX-022E31pl\#14 x MYR-29), a superioridade é explicada pelos altos valores da CGC de ambos os genitores (masculinos e femininos), ao passo que para $\mathrm{F}_{1}$ (PIM-013 x L-006), apenas o genitor masculino L-006 apresentou valor positivo. Por outro lado, para os híbridos $\mathrm{F}_{1}$ (L-005 x L-004) e $\mathrm{F}_{1}$ (MAGDA x L-004) cujos genitores apresentaram estimativas positivas e elevadas, a CEC, embora seja, em média, não-significativa (Tabela 1), foi alta em comparação aos demais, sugerindo que nesta combinação os efeitos não-aditivos também foram importantes no comportamento desses híbridos. O predomínio de efeitos gênicos aditivos controlando o caráter discorda dos resultados de Innecco (1995), que encontrou maior importância dos efeitos gênicos não-aditivos. Por outro lado, Tavares (1993), Soares (1995), Miranda et al. (1998) e Bonetti (2002) relataram maior influência dos efeitos gênicos aditivos no caráter, concordando com os resultados do presente ensaio.

\section{Presença de estrias epidérmicas no fruto}

As estimativas da CGC para o caráter foram de pequena magnitude (Tabela 3). Vale ressaltar que estimativas negativas são desejáveis, pois indicam que o genitor contribui favoravelmente na redução do caráter. Considerando as estimativas para CGC, no grupo dos genitores femininos $\left(\mathrm{g}_{\mathrm{i}}\right)$, os valores variaram de $-0,128$ a 0,603 (amplitude de 0,731 ), ao passo que, no grupo

Ciênc. agrotec., Lavras, v. 28, n. 2, p. 251-260, mar./abr., 2004 
dos genitores masculinos, a CGC $\left(\mathrm{g}_{\mathrm{j}}\right)$ variou de $-0,274 \mathrm{a}$ 0,304 (amplitude de 0,608), apresentando comportamento semelhante nos dois grupos de genitores para o caráter. Individualmente, destacam-se os genitores L005, MAGDA, PIX-021G_0818pl\#01 e PIM-014, com valores respectivos de $-0,017,-0,028,-0,111$ e $-0,128$, ao passo que nos genitores masculinos MYR-29 e L006, também contribuíram favoravelmente para a redução da expressão do caráter (Tabela 3).

As estimativas da CEC variaram de $-0,285$ a 0,391 (amplitude de 0,676), o que, embora representativos em relação à média $(\mu=1,811)$, não foram estatisticamente significativas para o caráter (Tabela 3 ). Pelos resultados obtidos, infere-se predomínio dos efeitos gênicos aditivos controlando a presença de estrias nos frutos, concordando, portanto, com os resultados de Bonetti (2002).

\section{Profundidade de inserção do pendúculo floral (PIP)}

Estimativas negativas de CGC indicam tendência dos genitores em proporcionar frutos com menor PIP, o que é desejável (Tabela 3). Entre os genitores femininos $\left(\mathrm{g}_{\mathrm{i}}\right)$, as estimativas da CGC variaram de -0,486 a 0,280 (amplitude de 0,766), ao passo que, no grupo de genitores masculinos $\left(\mathrm{g}_{\mathrm{j}}\right)$, variaram de $-0,223$ a 0,284 (amplitude de 0,507). Aparentemente, os genitores femininos apresentaram maior influência na média do caráter, destacando-se favoravelmente MAGDA e PIX021G_0818pl\#01, com valores respectivos de $-0,256$ e $-0,486$. Entre os genitores masculinos $\left(\mathrm{g}_{\mathrm{j}}\right)$, destacaram-se MYR-29 (-0,061) e L-006, (-0,223).

As estimativas da CEC variaram de $-0,159$ a 0,152 (amplitude de 0,357), valores pouco representativos em relação ao comportamento médio do caráter $(\mu=2,069)$, que se revelaram não-significativos (Tabela 1). Efeitos aditivos parecem controlar o caráter, o que concorda com os resultados apresentados por Bonetti (2002), porém, discorda dos de Innecco (1995), que encontrou também efeitos gênicos não-aditivos no controle de PIP.

\section{Altura de plantas aos 187 dias após a emergência (ALT)}

Nos grupo genitores feminino $\left(\mathrm{g}_{\mathrm{i}}\right)$, a CGC variou de -10,257 a 7,011 cm (amplitude de 17,367 $\mathrm{cm}$ ), ao passo que no grupo de genitores masculinos $\left(\mathrm{g}_{\mathrm{j}}\right)$ variou de $-4,079$ a $3,831 \mathrm{~cm}$, (amplitude de
$7,910 \mathrm{~cm}$ ) (Tabela 3). Com esses resultados infere-se que, aparentemente, os genitores femininos, quando comparados com os genitores masculinos aqui utilizados, apresentaram maior influência na média do caráter.

Os efeitos da CEC's não foram significativos (Tabela 1) e suas estimativas variaram de $-6,454 \mathrm{~cm}$ a $5,814 \mathrm{~cm}$ (amplitude de 12,268 cm), que é pouco relevante diante da média geral $(\mu=105,719 \mathrm{~cm})$ (Tabela $3)$. Efeitos gênicos aditivos controlando o caráter concordam com os resultados de Bonetti (2002), ao passo que a maior importância dos efeitos de natureza nãoaditiva concorda com Tavares (1993), Soares (1997) e Miranda et al. (1998).

\section{CONCLUSÕES}

a) Os efeitos gênicos aditivos foram importantes para todos os caracteres avaliados.

b) Para produção total de frutos, além dos efeitos gênicos aditivos, os não-aditivos foram significativamente de grande importância.

c) O testador MYR-29 possui boa capacidade combinatória com a maioria dos genitores do grupo 1, para os caracteres considerados, superando os testadores L-004 e L-006.

d) Os híbridos $\mathrm{F}_{1}$ (PIM-013 x MYR-29) e $\mathrm{F}_{1}$ (PIX-022E31pl\#14 x MYR-29) destacaram-se por serem valores favoráveis de CGC e CEC, tanto para produção quanto para características de frutos.

\section{REFERÊNCIAS BIBLIOGRÁFICAS}

BONETTI, M. L. G. Z. Heterose e capacidade combinatória de linhagens de híbridos de pimentão (Capsicum annuum L.). 2002. 85 p. Tese (Doutorado em Genética e Melhoramento de Plantas) - Universidade Federal de Lavras, Lavras, 2002.

CATIGLIONI, V. B. R.; OLIVEIRA, M. F.; ARIAS, C. A. A. Análise da capacidade combinatória entre linhagens de girassol. Pesquisa Agropecuária Brasileira, Brasília, v. 34, n. 6, p. 981-988, jun. 1999.

CRUZ, C. D.; CARNEIRO, P. C. S. Modelos biométricos aplicados ao melhoramento genético. Viçosa: UFV, 2003. 340 p.

HOLLAND, J. B. Epistasis and plant breeding. In: JAHICK, J. (Ed.). Plant breeding reviews. New York: John Wiley \& Sons, 2001. v. 21, p. 27-92. 
INNECCO, R. Avaliação do potencial agronômico de híbridos e capacidade combinatória de linhagens de pimentão (Capsicum annuum L.). 1995. 113 f. Tese (Doutorado em Fitotecnia) - Universidade Federal de Lavras, Lavras, 1995.

MALUF, W. R.; BLANK, A. F.; GOMES, L. A. A. Teste precoce da capacidade combinatoria de linhagens de pimentão (Capsicum annuum L.) para características de fruto. Ciência e Agrotecnologia, Lavras, v. 23, n. 1, p. 152-169, 1999.

MELO, A. M. T. Análise genética de caracteres de fruto em híbridos de pimentão. 1997. 112 f. Tese (Doutorado em Genética e Melhoramento de Plantas) Escola Superior de Agricultura Luís de Queiroz, Piracicaba, 1997.

MIRANDA, J. E. C.; COSTA, C. P.; CRUZ, C. D. Análise dialélica em pimentão. I: capacidade combinatória. Revista Brasileira de Genética, Ribeirão Preto, v. 11, p. 431-440, 1998.

OLIVEIRA, V. R. Capacidade de combinação entre linhagens de pimentão diferindo na tolerância ao baixo e alto teor de fósforo no solo. Bragantia, Campinas, v. 57, n. 2, p. 203-214, 1998.
SCOTT, T. J.; KNOTT, M. A cluster analysis methods for grouping means in the analysis of variance. Biometrics, Raleigh, v. 30, n. 3, p. 507-512, 1974.

SOARES, L. Divergência genética com base em componentes principais modificados e análise dialélica em pimentão (Capsicum annuum L.). 1995. 213 f. Tese (Doutorado em Genética e Melhoramento de Plantas) - Universidade Federal de Viçosa, Viçosa, 1995.

TAVARES, M. Heterose e estimativa de parâmetros genéticos em um cruzamento dialélico de pimentão (Capsicum annuum L.). 1993. 83 f. Dissertação (Mestrado em Genética e Melhoramento de Plantas) - Escola Superior de Agricultura de Lavras, Lavras, 1993.

VALLE, L. A. C. Avaliação da resistência de híbridos experimentais de pimentão ao mosaico amarelo causado por Pepper yellow mosaic virus (PepYMV). Horticultura Brasileira, Brasília, v. 20, n. 2, p. 346347, 2002a. Suplemento 1.

VALLE, L. A. C. Avaliação da resistência de híbridos experimentais de pimentão a Phythophtora capsici. Horticultura Brasileira, Brasília, v. 20, n. 2, p. 346347, 2002b. Suplemento 1. 